\title{
Coleções etnográficas, povos indígenas e práticas de representação: as mudanças nos processos museais com as experiências colaborativas
}

\author{
Adriana Russi \\ Professora Doutora da Universidade Federal Fluminense, Niterói, Brasil \\ adri.russitm@gmail.com
}

Resumo A partir das recentes políticas culturais voltadas aos ameríndios e ao patrimônio cultural, e das contribuições da museologia crítica, percebemos os embates nas relações entre museus, universidades e ameríndios. No contexto dos povos indígenas, como indicam Lucia Van Velthem e Regina Abreu, conhecer as peças fabricadas por seus ancestrais é um dos meios para compreender seu passado e refletir sobre seu presente e futuro. Conforme tais autoras, nos últimos anos, os ameríndios tomaram consciência dos museus e de suas coleções. $\mathrm{Na}$ atualidade, certos processos museais colaborativos incorporam a participação de indígenas. Os impactos dessas experiências no ambiente dos museus de antropologia e das universidades revelam uma complexa rede de relações e apontam para os desafios desse tipo de mediação cultural. Com isso, novas questões se colocam aos pesquisadores e se intensifica o debate contemporâneo sobre a relação entre os diferentes atores, circuitos e políticas de representação.

Palavras-chave: Museologia colaborativa, povos indígenas, coleções etnográficas, mediação cultural, patrimônio cultural.

\section{Introdução}

As discussões sobre processos museais colaborativos, que incluem em sua dinâmica os chamados "outros", remetem à reviravolta teórico-epistemológica que ocorreu no campo da museologia e da própria antropologia provocada por movimentos de repensar os fazeres e os discursos produzidos pelas ciências sociais em geral e pelas ciências sociais aplicadas, particularmente pela museologia. Os museus de antropologia certamente foram impactados 
pelo Movimento da Nova Museologia, ${ }^{1}$ da Museologia Social ${ }^{2}$ e, mais recentemente, da Museologia Crítica. ${ }^{3}$

Assim, se considerarmos apenas os museus de antropologia ou etnográficos, a partir dos anos 1990, prolongando-se para além da virada do século XXI, vimos na pauta uma revisão sobre sua função social, sua forma de expor e apresentar/ representar o "outro" e seu lugar na conservação e produção de conhecimento. Novas práticas e processos museológicos começaram a ser experimentados. Seria uma "antropologia feita no museu ou uma antropologia dos museus?” - indagou Kaplan (1996, p. 813) há 20 anos. Desde então, as investigações se voltaram para os próprios museus e suas práticas museológicas, o que se evidencia, por exemplo, pelos chamados museum studies ou estudos de museus.

Os museus etnográficos, que ao longo de séculos foram lócus de representação do "outro" e de discursos coloniais, desde então têm sido muito criticados por suas práticas museais tradicionais. A noção de fronteira como um "entre lugar", apenas para citar um conceito importante, por exemplo, para Homi Bhabha (1998), suscitou um questionamento quase existencial para estes equipamentos culturais. A colonialidade se faz presente hoje em países que há décadas são ex-colônias como uma espécie de fantasma do passado. Como repensar instituições em geral e museus, em particular, em práticas de

1 Conforme Desvallées e Mairesse (2013, p. 63), o Movimento da Nova Museologia (MINOM) que perdura até hoje, surgiu no Quebéc em 1984 e se institucionalizou em 1985 em Portugal. É um movimento ideológico dos anos de 1980, decorrente de precursores dos anos de 1970 e que chamava a atenção para a função social dos museus e de seu caráter interdisciplinar. Demonstravam forte interesse em novos formatos de museus como os ecomuseus, museus de sociedade e outros que tinham como um dos principais propósitos usar o patrimônio cultural para o desenvolvimento local. Para Duarte (2013, p. 99), “A Nova Museologia é um movimento de larga abrangência teórica e metodológica, cujos posicionamentos são ainda centrais para a efetiva renovação de todos os museus do século XXI.” A expressão “ecomuseu” cunhada por Hugues de Varine sintetizava, em certa medida, uma série de proposições de George Henri Rivière para o campo dos museus e vai ser um dos pontos centrais de discussão da Nova Museologia. Sobre o Movimento da Nova Museologia ver Duarte (2013). Sobre o uso do patrimônio para o benefício social verVarine (2013).

2 Resumidamente, a museologia social pode ser explicada como um esforço de adequação dos museus à sociedade contemporânea. Um importante momento desta perspectiva foi proferido em 1989, em Haia, por Frederic Mayor, por ocasião da abertura da XV Conferência Geral do ICOM - International Council of Museums. A principal intenção da museologia social é a de aproximar os museus da sociedade e de suas questões contemporâneas. Naquele momento, esta perspectiva foi tomada como uma "revolução museológica", caracterizada pelo surgimento de diferentes tipos de museus, como os museus comunitários, museus sem muro, ecomuseus e outros. Sobre museologia social ver Moutinho (1993), Chagas e Gouveia (2014).

3 Poderíamos identificar nos trabalhos de Bourdieu (2007) uma geração de pesquisadores que se voltou a estudos críticos dos museus. Em sua pesquisa, Bourdieu aponta para a inacessibilidade dos museus para as classes populares. Outro pesquisador crítico sobre os museus foi Anderson (2008), que identificou a relevância do papel dos museus na construção do ideal nacional. A chamada museologia crítica, proposta por Mestre e Cardona (2006) aponta as incongruências e contradições dos processos museológicos. 
decolonização? A partir das teorias do pós colonialismo, ${ }^{4}$ avançamos na reflexão crítica de onde emergiu a chamada Museologia crítica (Mestre; Cardona, 2006). Esta teoria defende o museu como cúmplice e não exclusivamente como autoridade e lugar de representação do "outro". Se considerarmos a diferença cultural como reivindica Bhabha, notaremos que os processos de significação no ambiente museal se dão em campos de forças nem sempre equilibrados.

À luz desta museologia crítica, neste artigo pretendemos tratar brevemente sobre a retomada dos objetos e de suas materialidades, provocada por práticas museais colaborativas. Poderíamos dizer com isso que nos debruçamos sobre uma breve revisão de processos museais experimentados em diferentes contextos e com características variadas e, genericamente, denominados por "museologia colaborativa". Para tanto, circunscrevemos nossa análise às reflexões de alguns autores, predominantemente antropólogos, acerca dos processos colaborativos que se desenvolvem entre museus e povos indígenas.

No universo dos museus de antropologia, com o advento da museologia colaborativa e de suas relações com os povos indígenas, tudo indica que se delineiam novos desafios para a mediação cultural.A presente reflexão decorre de pesquisa ainda em fase preliminar sobre estes novos processos museais em museus de antropologia em nosso país. Nesta análise privilegiamos alguns interlocutores que atuam no contexto brasileiro, como Regina Abreu (2007), Lucia Van Velthem (2012), Marilia Cury, Camilo de Mello Vasconcellos e Joana Montero Ortiz (2012), Renato Athias (2015) e Lima Filho e Athias (2016) bem como autores estrangeiros que têm nos inspirado a pensar sobre a problemática deste tipo de museologia. Entre eles destacamos as contribuições de Michael Ames (1990), James Clifford (1997), Marshall Sahlins (1997) e Cristina Kreps (2003).

Contemporaneamente, o que tem movido nosso interesse se baseia no questionamento sobre os impactos da Nova Museologia e da Museologia Social e inúmeras experiências colaborativas no universo dos museus de antropologia. Nesse contexto, percebemos a intrincada rede de relações entre esses museus, povos indígenas e universidades que provoca um interessante campo de discussão. Nos processos museológicos colaborativos e nos circuitos de representação observamos, por um lado, embates e disputas, e por outro,

4 De forma muito resumida no pós-Segunda Guerra Mundial, o poder dos países europeus que ainda mantinham suas colônias no continente asiático e africano se enfraqueceu. Paralelamente ao fortalecimento no cenário internacional dos Estados Unidos, muitas ex-colônias se tornaram independentes dando início a um fenômeno analisado tanto por autores pós-coloniais quanto pelos decoloniais. Muitos autores com diferentes trajetórias e formas de análise denunciam as relações antagônicas entre colonizador e colonizado, expressando as diferentes formas de dominação e opressão destes povos. Entre eles Bhabha (1998), aqui já referido, além de autores como Stuart Hall (2009) e Edward Said (2007). Na década de 1990, intelectuais latino-americanos que viviam nos Estados Unidos criticaram os modelos teóricos inspirados majoritariamente em autores europeus e eurocêntricos. Se por um lado os autores pós-coloniais se aproximaram das correntes pós-modernas e pós-estruturalistas, os autores decoloniais estão associados a projetos e autores de esquerda. Neste sentido, estes últimos buscam uma articulação interdisciplinar e uma emancipação teórico-intelectual 
diálogos e desafios. Observamos ainda que tais práticas se deparam com um crescente desafio frente às dificuldades impostas pelo ambiente institucional dos museus para acolher o dissenso como elemento potente e gerador de múltiplas perspectivas.

\section{Museus de antropologia: das coleções às práticas de representação decoloniais}

Segundo o Instituto Brasileiro de Museus (Ibram), o panorama museal brasileiro é hoje constituído por mais de 3 mil museus, dos quais aproximadamente 450 estão classificados na tipologia "antropologia e etnografia” (Ibram, 2011). Conforme o "Guia dos Museus Brasileiros”, são considerados museus de antropologia e etnografia aqueles que têm: "coleções relacionadas às diversas etnias, voltadas para o estudo antropológico e social das diferentes culturas. Ex: acervos folclóricos, artes e tradições populares, indígenas, afro-brasileiras, do homem americano, do homem do sertão etc.” (Ibram, 2011, p. 19).

Pesquisadores como Lucia Van Velthem (2012), Renato Athias (2015), Marilia Cury, Camilo Vasconcellos, Joana Ortiz (2012), Regina Abreu (2007), entre outros, afirmam que alguns desses museus têm questionado e mudado algumas de suas práticas museológicas. Esses autores observam que particularmente os processos museológicos relacionados aos grupos e/ou povos representados em suas coleções etnográficas, os chamados “outros”, têm passado por mudanças.

A partir da experiência do levantamento de coleções etnográficas dos ameríndios Katxuyana no Brasil e na Europa, ocorrido durante meu doutoramento e durante pesquisa de iniciação científica (Russi; Kieffer Døssing; Endreffy, 2016), acompanhei o anseio do povo Katxuyana para conhecer os objetos guardados nos museus. Os Katxuyana, ameríndios da família Karib, vivem no norte do Brasil.As pesquisas envolveram moradores nas aldeias Santidade e Chapéu, localizadas em Oriximiná, no oeste do Estado do Pará. No transcurso das pesquisas, algumas lideranças viram fotografias dos objetos musealizados e conversaram com os anciões e com os demais moradores das aldeias sobre isso. Nesse caso, esse desejo de verem fotografias dos objetos musealizados e conhecerem o que seus antepassados confeccionaram se insere num complexo processo vivenciado por este povo, de valorização de sua cultura ou, como eles dizem, de resgate da cultura katxuyana para garantir seu kwe'tohkumu. ${ }^{5}$

Em seu conjunto, as coleções somam cerca de 711 objetos entre plumária, cerâmica, adornos, artefatos de caça e pesca, armas, trançados e outros. Destes, 200 estão no Brasil e 511 na Europa. Os objetos etnográficos foram coletados por estrangeiros e brasileiros entre o final dos anos de 1920 a meados da década de 1970.

5 Apreendida a partir da expressão "cultura" (entre aspas), como explicada por Carneiro da Cunha (2009), poderíamos traduzir a expressão katxuyana como "nosso jeito de ser e viver", remetendo ainda à forma de viver de gerações passadas. Por isso, tal expressão seria também sinônimo do termo "tradição" tal como propõe Grünewald (2012). Sobre o processo de autovalorização cultural dos Katxuyana ver Russi (2014). 
A coleção mais antiga está no Brasil, no Museu Nacional de História Natural da Quinta da Boa Vista, no Rio de Janeiro. Datada do final dos anos de 1920 é uma das menores coleções, com 46 artefatos. A maior coleção com cerca de 220 objetos está no Nationalmuseet, em Copenhagen, na Dinamarca. As demais coleções estão assim localizadas:

- Museu Paraense Emilio Goeldi, em Belém-PA/Brasil - maior coleção do país com 154 artefatos;

- British Museum, em Londres/Inglaterra - a coleção tem 100 artefatos;

- Kulturhistorisk Museum, em Oslo/Noruega - 97 artefatos;

- Museumfür Völkerkunde, em Hamburg/Alemanha - 72 artefatos;

- Moesgaard Museum, em Århus/Dinamarca - a menor das coleções, com 22 objetos.

Instigadas pelo interesse manifestado por membros do povo Katxuyana, preparamos materiais digitais que resultaram do mapeamento dessas coleções ${ }^{6}$ e foram entregues não apenas aos museus, mas especialmente aos próprios Katxuyana. Lideranças deste povo, juntamente com seus anciões, têm mostrado esse material aos jovens de suas aldeias. Com isso, esse processo nos faz pensar sobre as possíveis apropriações desse material pelos Katxuyana em seu processo de valorização cultural. Tal investigação aponta para a possibilidade de novos sentidos dessas coleções e para a problematização dos processos de musealização dos artefatos indígenas na contemporaneidade. As pesquisas sobre as coleções etnográficas procuraram discutir seus sentidos contemporâneos e as possíveis requalificações, considerando as recentes aproximações com os Katxuyana. Apesar disso, reconhecemos que os produtos gerados pelas pesquisas (artigos, papers para congressos etc.) são inadequados para um diálogo mais horizontal com os Katuxyana. Embora os registros fotográficos das coleções estejam sendo apropriados pelos Katuxyana, os produtos da pesquisa pouco favorecem uma verdadeira articulação entre os agentes - pesquisadores, museus e indígenas -, gerando angústia e desapontamento frente às expectativas iniciais.

Por outro lado, este caso se mostra similar a inúmeros outros que ocorrem entre povos indígenas que desejam conhecer as coleções com objetos elaborados por seus ancestrais e preservados em museus. Neste sentido, a leitura dos estudos deVelthem (2003, 2012), Abreu (2005b), Lima Filho e Athias (2016), Cury (2016a, 2016b) e outros nos permite fazer tal afirmação. De forma bastante geral, muitos povos indígenas no Brasil vivem experiências de autovalorização cultural de distintas formas para preservar suas culturas e seus patrimônios culturais. Para vários povos conhecer os objetos musealizados faz parte desses processos.

Como destacam Velthem (2003) e Abreu (2005b), nos últimos anos, os povos indígenas tomaram consciência dos museus e de suas coleções etnográficas. Conforme

6 O mapeamento das coleções e de suas formações resultou de duas investigações: "Dos museus aos sujeitos: levantamento das coleções etnográficas dos Katxuyana” (Russi; Kieffer Døssing; Endreffy, 2016), no âmbito da iniciação científica da UFF, com a supervisão da Prof ${ }^{a}$. Dr ${ }^{a}$. Adriana Russi e participação da bolsista Marcela Endreffy; e a pesquisa de mestrado de Astrid Kieffer-Døssing (2016): "Re-assembling the Katxuyana collections: ananalysis of past, presentand possible futures of the Katxuyana collections as assemblages”, desenvolvida na Århus University. 
tais autoras, ver e conhecer as peças confeccionadas por seus ancestrais seria uma das maneiras que os povos indígenas têm para compreender o tempo de seus ancestrais e, a partir dessa experiência, refletir sobre seu presente e futuro. Isso nos remete à ideia de Varine (2013) sobre as "raízes do futuro", identificadas nas práticas patrimoniais. Dessa forma, os museus de antropologia se tornaram "lugares onde novos significados podem ser atribuídos aos movimentos de preservação cultural e de afirmação de identidades." (Velthem, 2012, p. 58).

Ainda conformeVelthem (2012, p. 52), os objetos etnográficos são "coisas recolhidas, deslocadas, guardadas." Coletados entre diferentes povos, tais objetos foram amealhados no transcorrer dos tempos e se constituíram em coleções públicas ou privadas, concebidas a partir de distintas políticas de representação do "outro".

Muitas foram as perspectivas epistemológicas decorrentes dos estudos das coleções etnográficas e suas relações com a cultura humana. Sabemos que os museus de antropologia sempre tiveram importante papel na preservação do patrimônio material. Por outro lado, por muito tempo tais instituições assumiram discursos centrados nas perspectivas dos colonizadores.

Em suas origens, esses museus estavam de tal forma imbricados com a antropologia que revelam as implicações epistemológicas do próprio saber antropológico. Essa relação entre museus, antropologia e saber antropológico foi analisada por inúmeros autores (Gordon; Silva, 2005; Arantes Neto, 2005; Dias, 2013; Schwarcz, 2013; etc.) e não caberia aqui retomá-las. Entretanto, uma breve síntese se mostra oportuna nessa discussão. Gordon e Silva (2005) e Cury e Silva (2008) esquadrinharam de forma sintética e objetiva os três principais períodos da própria disciplina antropológica:pré-moderno (ênfase na orientação teórica evolucionista, pesquisas em arquivos e documentos; colecionismo); moderno (ensejado pelo trabalho de campo etnográfico quando as coleções eram correlacionadas à organização e classificação); e pós-moderno (crítica à escrita etnográfica e aos museus considerados testemunhos do colonialismo).

A partir da análise da história da museologia, verificamos que os museus etnográficos e suas coleções foram apropriados de distintas maneiras. Desde a criação dos primeiros museus etnográficos na Europa no século XIX - tal como o seminal Musée d'Ethnografie du Trocadéro, fundado em Paris em 1878 - até os dias de hoje, os objetos e as coleções passaram por diferentes concepções, como bem sintetiza Augusti Tomàs (2012, p. 106):

Desde el siglo XIX hasta el siglo XX la renovación de los museos de etnologia se ha llevado a cabo, también, a partir de diferentes maneras de interpretar el patrimonio etnológico: ya sea para mostrar estádios culturales, áreas, para presentar el progreso técnico, para mostrar las identidades culturales o, entre otros, para explicar la diversidad cultural o hacer un ejercicio de crítica cultural. ${ }^{7}$

7 Tradução livre: "Desde o século XIX até o século XX, a renovação dos museus de etnologia também foi realizada através de diferentes formas de interpretação do patrimônio etnológico: quer para mostrar estágios culturais, áreas, apresentar progresso técnico, quer para mostrar identidades culturais ou, entre outros, explicar a diversidade cultural ou fazer um exercício de crítica cultural." 
No Brasil, as coleções indígenas presentes nos museus resultaram de doações de viajantes, militares, comerciantes, missionários e outros. Segundo Cannizzo (1998 apud Velthem, 2012, p. 54), as coleções etnográficas trazem à tona perspectivas ideológicas, pois se constituíram a partir de diferentes projetos, sobretudo coloniais. Nesse sentido:

Os acervos nacionais estão, assim, abarrotados de coleções etnográficas que patenteiam manifestações ideológicas. A reunião de objetos e as consequentes coleções constituem formas de visualização de ideologias que revelam o caráter das coletas e dos contatos. (Cannizzo, 1998 apud Velthem, 2012, p. 54).

Cada museu etnográfico segue determinados preceitos metodológicos e epistemológicos que orientam a coleta dos objetos e a forma de apresentá-los. De forma geral, os objetos são apresentados de diferentes maneiras, especialmente através de exposições que procuram seguir os objetivos norteadores dessas instituições. Sabemos, ainda, que as coleções etnográficas, a despeito de suas origens e contextos históricos, são testemunhos materiais de diferentes povos e estão sob a guarda, em sua maioria, de instituições museais responsáveis por sua preservação.

Para Beltrão (2003), esses testemunhos possuem valor documental, histórico e simbólico por expressarem a realidade material dos povos e permitirem a leitura das transformações ocorridas ao longo dos tempos. Nesse sentido, Thomas (2010, p. 8 apud Dias, 2013,p. 86) afirma:"Anthropological collections are always also historical collections; they are the products of, the evidence of, and maybe even the memorials to entangled histories." 8

Velthem (2012, p. 56) reforça a importância das coleções etnográficas para os estudos da humanidade e de suas culturas, ao afirmar que: "É inquestionável na antropologia que coleções de objetos etnográficos representam fontes de consulta importantes para um amplo leque de estudos interpretativos na área das ciências humanas." Se por um lado de fato as coleções são importantes nestas reflexões, não podemos tomá-las como dados atemporais e neutros. Urge problematizarmos a maneira como tais coleções se constituíram, contextualizando histórica, política e culturalmente tais empreendimentos. A ciência não é neutra e não foram neutras as formas de escolha, coleta e organização de objetos em coleções.

Assim, ao final do século XX tais instituições e suas inúmeras coleções sofreram duras críticas, pois se revelaram testemunhas materiais do colonialismo. Essas críticas provocaram uma crise no ambiente museal, que suscitou um debate sobre o papel de tais instituições e os circuitos de representação. Era preciso repensar o espaço do museu para além das pesquisas e exposições e torná-lo local de práticas de trabalhos mais colaborativos. Se consultarmos a história da museologia ocidental, verificaremos que nos anos de 1970 a 1980 ou até mesmo depois disso, foi enorme o impacto do movimento da nova museologia neste sentido. dutos de, a evidência de e talvez até memoriais para histórias emaranhadas." 
Historicamente, como apontam Françozo e Broekhoven (2017, p. 709), a reviravolta teórico-epistemológica no mundo dos museus se situa entre os anos de 1960 a 1970, articulada a outros movimentos sociais em defesa de direitos culturais de grupos minoritários, notadamente de negros e indígenas, inicialmente na sociedade estadounidense, mas que se difundiu rapidamente por outras ex-colônias da Inglaterra. Segundo as autoras:

As origens do movimento mais amplo de renovação do cenário políticocultural dos museus estão enraizadas nas décadas de 1960 e 1970, com as demandas políticas dos movimentos blackpower e redpower, tanto nos Estados Unidos, que entre outras conquistas, reconfiguraram as relações políticoculturais dentro daquele país. Desde então, tanto nos Estados Unidos como no Canadá, na Austrália e na Nova Zelândia, diversas comunidades indígenas passaram a exigir não só maior reconhecimento político para suas causas, mas também a possibilidade de participação efetiva (ou mesmo exclusiva) nas instituições nacionais de cultura, que até então detinham a autoridade para falar das sociedades, de seus modos de vida e das cosmologias indígenas. Em uma perspectiva global, pode-se dizer que a crítica pós-colonial gerou uma necessidade crescente de descolonização dos museus por todo o mundo. Do mesmo modo, no Brasil, desde a década de 1980 e notadamente após a promulgação da constituição de 1988, houve um crescimento significativo das demandas e das conquistas - atualmente ameaçadas - dos povos indígenas, incluindo-se aí a formação de plataformas culturais diversas que possibilitam as práticas de autodeterminação e a luta por território e reconhecimento (Françozo; Broekhoven, 2017, p. 709).

Assim, desde os anos de 1980 o mundo dos museus foi atravessado por uma série de mudanças que vão das arquiteturas espetaculares às grandes exposições populares, passando pela problematização das questões relacionadas aos visitantes e ao marketing dos museus (Desvallées; Mairesse, 2013).

Paralelamente àquele momento, teorias em torno da descolonização impactaram os processos museológicos e levaram a repensar o museu para além das pesquisas, questionando as formas de se mostrar o "outro". Na antropologia, por exemplo, James Clifford (2002) contestou a autoridade do etnógrafo. No campo da museologia, Christina Kreps (2003) apontou para a necessidade de uma prática curatorial baseada na perspectiva cross-cultural; ou seja, uma prática inter ou transcultural. Ambos os argumentos opõem-se ao discurso hegemônico presente nas exposições ao revelarem a ausência da perspectiva do "outro". As críticas se voltavam aos casos em que especialistas (antropólogos, museólogos e outros) e museus elaboravam curadorias de coleções e/ou de exposições representativas dos "outros" sem considerar as perspectivas desses "outros". Com isso, vimos o desenrolar de um intenso debate problematizando o discurso do colonizador e propondo formas de narrativas sobre o "outro" através de práticas polifônicas na concepção de exposições.

Para o movimento da nova museologia, o museu deve atuar tanto na preservação dos testemunhos materiais de povos que já não existem quanto numa museologia ativa e participativa que envolva os povos que hoje configuram a diversidade da humanidade. A nova museologia defende um fazer museológico interessado pelo desenvolvimento 
das populações, ao se articular aos seus projetos de futuro. Com essa proposição, outros caminhos e preocupações se incorporaram aos museus. O museu deixou de ser apenas local de conservação e pesquisa de objetos para se tornar lugar de processos museológicos dinâmicos e participativos. Assim, de instituições depositárias e preservadoras de objetos, os museus voltaram sua atenção ao público e à prática de uma museologia participativa (Varine, 2013).

No entendimento de Cândido (2003), para a nova museologia, os testemunhos materiais servem a explicações e experimentações mais que à formação de coleções. Para a autora, o fazer da nova museologia dá relevo à investigação social como forma de identificação de problemas e de soluções possíveis. Daí entender que encerradas nas reservas técnicas dos museus, as coleções pouco contribuem no cumprimento do papel social dessas instituições.

Experiências dessa natureza foram colocadas em marcha no Canadá por pesquisadores como Michael M.Ames (1990), que no final dos anos de 1980 trabalhou com os Kwakiult e os U'Mista (Ribeiro, 1994). Esse antropólogo sugeriu três formas de aproximação dos museus com os povos indígenas: a primeira delas estaria assentada no "poder cultural" dos povos para se "apoderarem" das coleções no sentido figurado; a segunda, pela possibilidade de "interpretações múltiplas" que articulam tanto a visão acadêmica quanto a visão nativa dos objetos; a terceira de que o museu deveria assumir responsabilidade à frente das "teorias críticas", de forma a questionar a situação contemporânea pela qual passam os povos representados nessas instituições.

Outra seminal experiência foi descrita por James Clifford (2016) em Museums as contact zone, obra publicada em 1997. Nesse texto, o autor relata o encontro ocorrido em 1989, no Museu de Arte de Portland (Oregon), entre um grupo de velhos tlingit, ${ }^{9}$ antropólogos e outros especialistas para conversarem sobre a coleção Rasmussen de arte Indígena da Costa Noroeste do museu.

Por ocasião da reinstalação da coleção no Museu, o então diretor do Instituto de Arte de Portland, Dan Monroe, sugeriu que a discussão incluísse lideranças tlingit. Assim, ao longo de três dias indígenas reviram muitos objetos confeccionados por seus ancestrais. Ao contrário do que se esperava, os indígenas usaram a ocasião para dar voz às suas questões contemporâneas. Os indígenas usaram os objetos como pretexto para contar suas histórias; os objetos foram aides-mémoire (Clifford, 2016, p. 2). Como apontou Clifford, os objetos foram bons elementos para suscitar questões que afligiam aquele povo, tais como a problemática do território e a regulação de seus recursos naturais por órgãos do governo. Eram questões políticas contemporâneas. As expectativas sobre aquele encontro eram muito diferentes. Para os indígenas era a oportunidade de estabelecerem alianças e parcerias com aqueles que ali se encontravam, dentre eles antropólogos, especialistas de arte, profissionais do museu na defesa de seus interesses.

9 Povo nativo norte-americano que vive na faixa litorânea e ilhas do Pacífico, na região que vai do sudeste do Alasca ao norte da Colúmbia Britânica, no Canadá (Clifford, 2016). 
Clifford (2016) indicou ainda as dificuldades que a equipe do museu enfrentaria a partir daquele encontro. Depois de tantas narrativas, danças e performances dos tlingit, que narrativa o museu deveria priorizar? $\mathrm{O}$ que deveria ser enfatizado na exposição? Clifford identificou diferentes agendas naquele encontro. Como acomodá-las num mesmo projeto, indagava o autor. Este universo das representações no ambiente museal é um universo de muitos agenciamentos e complexidades. Para Clifford (2016) são lugares de cruzamentos e seleções múltiplas, traduções e apropriações.

As diferentes posições e disputas entre povos nativos e museus provocou enorme debate no Canadá acerca dos parâmetros para a colaboração museológica. Parece que as armadilhas e os desafios para museus e antropólogos descritos por Clifford em seu texto de 1997 continuam candentes e atuais.

A partir de então, inúmeras experiências colaborativas sucederam estas. No transcorrer da primeira década do século XXI vimos surgir diferentes teorias e reflexões sobre processos museais colaborativos. Termos como decolonizing museums ${ }^{10}$ (Lonetree, 2012), unpacking the collection ${ }^{11}$ (Byrne et al., 2011) e reassembling the collection ${ }^{12}$ (Harrison, 2013) surgem nas teorias críticas e nas fronteiras entre museologia, antropologia e outros campos disciplinares.

Esse debate sobre o papel dos museus etnográficos e sua função social também se desenvolveu no Brasil. Para autores como Lima Filho e Athias (2016) e outros, mais recentemente vem se definindo um conjunto de preocupações em torno das contrarrepresentações dos grupos. Novas práticas entre museus e povos detentores dos patrimônios musealizados são experimentadas e trazem à tona limites e dificuldades.

Como indicam Françozo e Van Broekhoven (2017, p. 710), vários museus de antropologia no Brasil têm se dedicado a desenvolver experiências colaborativas com povos indígenas, entre eles: o Museu Paraense Emilio Goeldi; o Museu do Estado de Pernambuco; o Museu Antropológico da Universidade Federal de Goiás; o Museu Nacional do Rio de Janeiro; o Museu do Índio da Fundação Nacional do Índio; o Museu de Arqueologia e Etnologia da Universidade de São Paulo; o Museu de Etnologia e Arqueologia da Universidade Federal do Paraná; e o Museu de Arqueologia e Etnologia da Universidade de Santa Catarina.

Acompanhamos, assim, processos museais colaborativos, denominados genericamente pela expressão "museologia colaborativa" e que decorrem de vertentes teóricas da nova museologia e da antropologia engajada. O termo "museologia compartilhada" é bastante abrangente e se refere, de forma geral, a diferentes tipos de processos museológicos que

10 A expressão, que em português traduziríamos livremente como "decolonização de museus", é empregada por Amy Lonetree como uma preocupação da área dos museum studies sobre a participação de povos indígenas em processos museais.

11 Nessa coletânea, cujo tema central traduziríamos como "desembalando as coleções”, está presente a ideia de agência dos objetos, profissionais e povos e as relações sociais na história dos museus. A ênfase recai na perspectiva das relações interculturais.

12 Essa expressão poderia ser traduzida como "remontando a coleção". 
resultam de interação e troca entre profissionais de instituições culturais, particularmente museológicas, e diferentes sujeitos. Esses sujeitos podem ser profissionais de diversos setores dos museus, como aqueles que trabalham na área da educação museal, artistas cujas obras serão exibidas nos museus, mas, sobretudo, diferentes grupos ou comunidades que, de alguma maneira, têm algum vínculo com o museu, etc. Dutra (2014), por exemplo, analisa esse fenômeno na perspectiva da "curadoria compartilhada".

Nestas experiências, os povos indígenas e inúmeros "outros" foram sendo, aos poucos, convidados a compartilhar seu conhecimento sobre os objetos a serem expostos num trabalho conjunto com curadores das exposições e com pesquisadores. No campo das relações entre pesquisadores e povos indígenas, citamos, por exemplo, o trabalho de antropólogas, como Lucia Van Velthem (2003), e de museólogas, como Marilia Cury (2016a).

Uma outra experiência colaborativa e que aqui podemos relatar brevemente é a da exposição "No caminho da miçanga: um mundo que se faz de contas", organizada pela antropóloga Els Lagrou. A partir de um longo trabalho que se estendeu por sete anos e que incluiu o efetivo trabalho e participação de diferentes grupos indígenas, instituições e outros pesquisadores, foi possível desenvolver: a ampliação do acervo do Museu do Índio do Rio de Janeiro - então com muitas ausências de peças com miçangas - e a elaboração de rica pesquisa e documentação sobre os objetos e seus contextos contemporâneos. Para a própria Els, a montagem da exposição se assemelha a uma "grande tecelagem”, “[...] uma densa rede de colaborações dos mais diversos agentes envolvidos na produção deste acervo e desta exposição, que finalmente, fechou seu longo ciclo e circulo.” (Lagrou, 2016, p. 20).

No Brasil, termos como "museologia social" ou "museologia comunitária"13 vêm ganhando projeção. Conforme o Ibram (2016, p. 6), há um excepcional crescimento da museologia comunitária no Brasil:

[...] que traz como foco sua função social, ressignificando os museus como espaços não apenas educativos e de convivência, pesquisa, exposição de acervos e coleções, mas também de formação política dos indivíduos e de comunidades engajadas no processo de forjar suas próprias narrativas museais. (Ibram, 2016, p. 6)

Apesar destas e de outras tantas experiências de processos que poderíamos denominar, de forma geral, como experiências de processos museais colaborativos, compartilhados,

13 A Museologia comunitária resultou de projetos implantados no México logo após a Mesa Redonda de Santiago em 1972. Tratavam-se dos projetos "A casa do museu" e os "Museus escolares". Este tipo de museologia coloca o museu como importante instrumento para o desenvolvimento social que se dá pela valorização do patrimônio cultural local. Por isso, a participação da população é imprescindível para seu pleno funcionamento. Os temas são escolhidos pela comunidade e revelam questões que lhes são pertinentes na atualidade. Um dos principais objetivos ainda é o de incrementar o desenvolvimento sustentável a partir do turismo cultural e de pequenas iniciativas locais e/ou familiares. Sobre museologia comunitária ver ainda Priosti e Mattos (2007). 
ou mais especificamente de etnomuseologia, ${ }^{14}$ parece que as exposições e a forma como os museus etnográficos se comunicam com seus variados públicos ainda se mostra como a principal questão que ocupa os debates dos museus de antropologia na contemporaneidade.

No Brasil, o termo "etnomuseologia" vem sendo empregado nas últimas décadas ainda de forma pouco conceitualizado. Em artigo aqui citado, Berta Ribeiro (1994) utiliza o termo sem explicitar claramente seus pressupostos teórico-metodológicos. Glenn Shepard (2012) emprega o termo para sintetizar alguns processos museais compartilhados com povos indígenas desenvolvidos recentemente pelo Museu Paraense Emilio Goeldi, em Belém, Estado do Pará. A partir de experiências no âmbito do Museu Goeldi, Shepard et al. (2017, p. 765) afirmam que a "etnomuseologia visa engajar os povos indígenas em um diálogo com sua cultura material." Os autores ressaltam ainda a diversidade de conceitos, expectativas e atitudes dos povos indígenas em relação às coleções etnográficas.

Parece que a expressão teria sido usada pela primeira vez na Romênia e na Tchecoslováquia nos anos de 1980. Certamente, o conceito decorre das mudanças provocadas no ambiente museal pelo movimento da nova museologia.

Importante aqui ainda destacar a recém publicação do Boletim Emilio Goeldi (Françozo; Broekhoven, 2017), cujo dossiê se dedica a analisar diferentes casos de museologia colaborativa sob a perspectiva do patrimônio indígena e das coleções etnográficas. Já na introdução, Françozo e Van Broekhoven (2017, p. 709) indicam a variedade de expectativas, caminhos e resultados nestes casos.

Reforçando a preocupação dos debates sobre os museus de antropologia e suas coleções, como apontam Lima Filho e Athias (2016), nos anos 2000 uma série de eventos internacionais ocuparam os debates de profissionais de museus e antropólogos. Entre eles destacamos alguns, como a conferência The Future of Ethnografic Museums Conference, realizada em Oxford no ano de 2013. No ano seguinte, ocorreu em Paris a 43ème Symposium Annuel d' ICOFOM, com o objetivo de discutir as novas tendências da museologia com ênfase para as questões da descolonização, a museologia participativa, com uma reflexão comum e interdisciplinar entre vários campos de saber. Ainda naquele ano, ocorreu em Barcelona o encontro Decolonising Museums. Tais eventos, com formatos e dimensões distintas, tinham entre os principais questionamentos a forma como os museus expõem os "outros", criticando o lugar privilegiado dos curadores e de suas perspectivas nas abordagens dos temas e nas narrativas das exposições. A polêmica seguida de inúmeros debates e críticas em torno do Musée du quai Branly, inaugurado em 2006 em Paris, parece ilustrar um pouco essa questão.

Por outro lado, vemos surgir mais recentemente, há cerca de pouco mais de uma década, um deslocamento do enfoque destas preocupações sobre práticas de representação,

14 Para outras referências sobre etnomuseologia, ver também: Simpson (2003), Stránsky (1981), Tapsell (2011). 
direito de acesso e repatriação. ${ }^{15}$ Nova perspectiva para este debate, não distanciada das questões acima mencionadas, inaugura outros processos entre museus e povos detentores dos patrimônios musealizados. Se antes a ênfase recaía em temas como museus etnográficos e seus públicos, e/ou museus etnográficos e exposições sobre o "outro", agora acompanhamos experiências no mundo todo de apropriações dos povos detentores desses patrimônios para fins de seus interesses.

Nessa perspectiva, em 1991, vimos surgir no Brasil o Museu Magüta:primeiro museu indígena concebido pelo povo Ticuna e instalado na cidade de Benjamim Constant, no Estado do Amazonas (Abreu, 2005b). Nos EUA, outro caso é aquele promovido pela Association of Tribal Archives, Libraries and Museums (Phoenix, Arizona-EUA) - as conferências internacionais -, quando são reunidos profissionais (indígenas ou não indígenas) de vários equipamentos culturais dos povos indígenas que vivem no território norte-americano. O Abbemuseum é um desses exemplos; outro é a plataforma Mukuru, que possibilita às comunidades gerenciarem, compartilharem e trocarem seus patrimônios culturais digitalizados.

Ainda exemplificando práticas de processos museais colaborativos com povos indígenas destacamos a exposição com título em guarani Dja Guata Porã, que traduzido para o português significa "o caminho se faz ao caminhar", e subtítulo "Rio de Janeiro indígena”. Essa exposição foi inaugurada em 2017 no Museu de Arte do Rio, na cidade do Rio de Janeiro. Concebida a partir do encontro de povos, aldeias e indígenas com profissionais do museu e pesquisadores ela decorreu de um diálogo conduzido entre 2016 e 2017. Essa curadoria se constituiu coletivamente no transcurso de um longo processo que demorou cerca de um ano até serem concebidos os eixos e circuitos da exposição. Integram a exposição diversos núcleos temáticos com obras, vídeos, fotografias e outros formatos narrativos e de representação associados a documentos e iconografia histórica. Quatro núcleos são dedicados a povos e indígenas que habitam o Estado do Rio: os Guarani, os Puri, os Pataxó, além de indígenas que moram no contexto urbano, como aqueles que ocupam a aldeia Maracanã. Na chave dos direitos culturais, a intenção da exposição é a de dar visibilidade às etnias indígenas que existem no Estado do Rio de Janeiro e que vivem em distintas circunstâncias e contextos: índios aldeados, índios urbanos, grupos de ressurgência e outros.

Esse exemplo ilustra bem a perspectiva cross cultural (Kreps, 2003), que aponta para a necessidade de processos museais mais colaborativos entre instituições e comunidades.

15 A polêmica que cerca a temática da repatriação do patrimônio material é tão extensa quanto variada. O leitor pode encontrar em diferentes instruções normativas internacionais e na Convenção da UNESCO de 1954 e de 1970 elementos importantes nesta discussão. Além disso, ainda no âmbito da UNESCO foi criado o Comitê Intergovernamental para a Promoção do Retorno dos Bens Culturais ao seu País de Origem ou Sua Restituição em caso de Apropriação Ilegal em 1978. Há ainda a Convenção de UNIDOIT, de 1995, que trata da repatriação, tráfico ilícito etc. Em 2016 o Governo Federal sancionou a Lei nº 13.254 de 13/01/2016, a chamada Lei da Repatriação. 
Como afirmou Marshall Sahlins (1997), inúmeros povos tradicionais em processos de valorização de sua cultura estão interessados em participar e assumir protagonismo em projetos que dizem respeito às suas culturas. Já no final dos anos de 1990, Sahlins (1997) indicava que o exercício de objetivação da cultura, por vezes ensejado por antropólogos durante suas investigações, levava a uma crescente contestação destes povos tradicionais acerca de ações que os envolviam. Destas contestações vimos a exigência por participações mais efetivas. Em uma de suas publicações, Regina Abreu (2005a) salienta a participação dos antropólogos nos processos de patrimonialização junto a esses povos. Abreu (2012) chama atenção para o surgimento daqueles que denominou por "novos sujeitos de direito coletivo". Nessa "antropologia nativa”, segundo Abreu (2007), esses povos fariam uma "antropofagia" dos meios, técnicas e processos de representação, protagonizando a musealização de seus patrimônios.

Corroboram com esta ideia Lima Filho e Athias (2016), que relatam o crescimento de experiências de apropriação dos indígenas dos espaços museológicos para fortalecimento de sua organização política no Brasil e no mundo. Outra autora que também aponta esta perspectiva é Marilia Cury (2013), para quem os museus atravessam um momento de transformações. Para Zavala (2003 apud Cury, 2013), os museus vivenciam um período de transição entre dois modelos: um museu tradicional e um museu emergente. São experimentações conceituais e metodológicas que estão em curso entre museus e povos indígenas.

Assim, verificamos na contemporaneidade o reconhecimento do valor das coleções etnográficas para além das pesquisas. Como expõe Velthem (2012) a partir de texto de Harkin (2005), no final do século XX surge no universo museal, em especial nos Estados Unidos e no Canadá, um debate político e intelectual sobre o papel dos povos indígenas nessas instituições. Cada vez mais, curadores, pesquisadores e os produtores dos objetos musealizados interagem de diferentes maneiras.

Dessa forma,Velthem (2012, p. 63) defende que:

[...] seria essencial o estabelecimento de uma redescoberta dos objetos etnográficos, ou melhor, é igualmente necessário descobrir-se outra coisa que não seja o seu caráter de objeto científico, documental. Através desta via, que representa de alguma forma uma ruptura, é possível conferir a esses objetos outro estatuto, o que abre a porta para um novo olhar sobre os mesmos.

Nessa mudança de perspectiva, os objetos etnográficos são um pretexto para se construir um discurso polifônico e não uma finalidade em si mesmo. 


\section{Coleções etnográficas e os circuitos de representação: desafios contemporâneos à mediação cultural}

No panorama dos cerca de 457 museus de antropologia no Brasil encontramos um universo muito diversificado de instituições, constituído por museus públicos e privados, de pequeno, médio ou grande porte. Muitos deles poderiam ser classificados como "tradicionais", outros como "ecomuseus" ou "museus comunitários". Há também os "museus universitários". Alguns têm como principal coleção os objetos etnográficos, outros são constituídos por diferentes tipologias de coleções, outros sequer tem um conjunto de objetos etnográficos. Certos museus estão instalados em edifícios de grandes dimensões, equipados com modernas reservas técnicas e conduzidos por um quadro profissional altamente qualificado. Outros se caracterizam por um amontoado de objetos, mal documentados e acondicionados e tem numa única pessoa, a figura responsável por quase todas as responsabilidades do museu.

Analisar os processos museais que envolvem povos indígenas nos leva a refletir também sobre as políticas de cultura. Apesar de muitos avanços na garantia dos direitos culturais dos povos indígenas que ocupam o território brasileiro, em recentes discussões (Museu do Índio, 2013), ficou evidente que ainda persistem inúmeras dificuldades para que se efetive o direito constitucional desses povos. $\mathrm{O}$ artigo $\mathrm{n}^{\mathrm{o}} 231$ da Constituição da República Federativa do Brasil garante aos povos indígenas o reconhecimento de "sua organização social, costumes, línguas, crenças e tradições, e os direitos originários sobre as terras que tradicionalmente ocupam." A gestão de patrimônios culturais indígenas, por conseguinte, deve se tornar uma preocupação central nas políticas públicas indigenistas e culturais no Brasil, hoje fortemente abaladas pela crise política e econômica que afeta nosso país. Essa tensão aponta muitos desafios ao campo da mediação cultural em museus antropológicos.

Refletir sobre as relações entre museus de antropologia, coleções e povos indígenas nos remete à noção de mediação cultural. Ao que parece, processos museológicos compartilhados entre museus de etnografia e povos indígenas seriam sinônimo de processos de mediação. Dessa forma, o termo mediação cultural se coloca importante na medida em que esses processos se revelam como um "entre-caminho": de um lado os museus etnográficos com seus acervos de objetos e/ou suas exposições e, de outro, grupos indígenas constituídos por gerações herdeiras dos produtores desses artefatos.

Apesar da importância do conceito de mediação, sabemos que ele é complexo, ainda está em construção e, por isso, merece cautela em seu uso, cabendo aqui uma breve referenciação. Uma noção bastante recorrente do termo mediação coaduna com aquela explicitada por Teixeira Coelho (2004), que embora muito difundida, parece não traduzir plenamente a complexidade contemporânea do fenômeno da mediação.

Para Coelho (2004), mediação cultural se refere a: "Processos de diferente natureza [sic] cuja meta é promover a aproximação entre indivíduos ou coletividades e obras de culturas e arte. [...] é feita com o objetivo de facilitar a compreensão da obra [...]." (Coelho, 
2004, p. 248). Tal explicação, que carrega a marca de seu tempo, parece remeter a uma ideia de receptor pouco ativo nas atividades culturais e dependente da condução de um “circuito" cultural mediado por outrem ou por uma instituição. Nessa concepção, como o próprio autor (Coelho, 2004) identifica, são termos relacionados à mediação cultural, entre outros, a animação cultural e a fabricação cultural. Ora, se por um lado concordamos que nessa complexa rede de relações entre agentes e instituições ocorrem aproximações entre os "outros" e os objetos etnográficos, nos parece que muitas experiências de processos museais colaborativos não se restringem a processos "facilitadores" da compreensão da obra, ou seja, dos objetos musealizados.

A expressão "mediação cultural" também é empregada na referência de experiências de ações educativas no campo dos museus. No Brasil, por exemplo, vemos se consolidar uma ampla rede de profissionais envolvidos nessas atividades de educação não formal em espaços culturais e museológicos - a Rede de Educadores de Museus (REM) Nacional -, atualmente articulada ao Programa Nacional de Educação Museal (PNEM) do Ibram. Em alguns casos, essas atividades de mediação cultural ocorrem sob a nomenclatura "educação patrimonial" (Dutra, 2014). Por outro lado, cabe destacar que "mediação cultural" e "educação patrimonial" 16 não podem ser tomadas como sinônimos.

Entretanto, a questão se torna mais complexa ao lembrarmos que a curiosidade de nossa reflexão recai em um público não convencional aos museus: os grupos indígenas. Os povos indígenas são um público minoritário e pouco convencional ao ambiente museal. Historicamente foram alijados destes espaços sendo, portanto, pouco frequentadores destes equipamentos culturais se comparados a outros públicos. ${ }^{17}$ Além disso, de alguma maneira estão inter-relacionados aos próprios objetos, expostos ou guardados nas reservas técnicas dos museus.

Conforme Desvallées e Mairesse (2013, p. 52), a mediação remete a uma ação de intercessão que coloca em acordo duas ou várias partes. No campo dos museus, seguindo esses autores, a mediação seria aquilo que é dado a ver ao público. Assim, a mediação:

[...] se coloca "entre dois", em um espaço que ela buscará reduzir, provocando uma aproximação ou, dito de outro modo, uma relação de apropriação. [...] No campo cultural, a mediação intervém sempre para analisar a "apresentação ao público" das ideias e produtos culturais - sua apropriação midiática - e descrever a sua circulação no espaço social global (Desvallées; Mairesse, 2013, p. 52-53).

Essa noção parece se aproximar daquela descrita por Coelho (2004).Aqui destacamos ainda a noção que o termo mediação cultural assume no campo da museologia, particularmente difundido na França e países francófonos (Desvallées; Mairesse, 2013).

16 Sobre educação patrimonial ver Silveira; Bezerra (2007).

17 Há muitos estudos sobre museus e públicos e sobre fatores na formação do indivíduo que favorecem sua prática cultural. Bourdieu (2007), em sua pesquisa, evidencia o papel da cultura na dinâmica social e desta nas práticas e gostos culturais; o chamado capital cultural. 
Nesse caso, a mediação compreende diferentes intervenções que ocorrem no contexto museal com o objetivo de estabelecer contato entre o que é exposto e seus significados.

Trata-se, então, de uma estratégia de comunicação com caráter educativo, que mobiliza as técnicas diversas em torno das coleções expostas, para fornecer aos visitantes os meios de melhor compreender certas dimensões das coleções e de compartilhar as apropriações feitas (Desvallées; Mairesse, 2013, p. 53).

Procuramos, então, problematizar esse termo, ampliando seu escopo um pouco mais ao refletir sobre quais intervenções os museus etnográficos poderiam ensejar ou o que eles têm feito com grupos indígenas a partir de suas coleções. Por isso, um dos elementos que nos interessa compreender seria como se dão essas relações em casos em que esse público é formado por grupos indígenas, cujos ancestrais produziram aqueles artefatos que hoje integram dada coleção em um museu. Assim, queremos incluir a noção de interpretação a que o termo mediação está associado na língua inglesa. Neste sentido, mediação designa "o caráter hermenêutico das experiências de visita a museus e sítios" (Desvallées; Mairesse, 2013, p. 54).

Para Perrotti:

O conceito de mediação cultural emerge na contemporaneidade como formulação teórica e metodológica inscrita, portanto, num quadro que reconhece os conflitos, ao mesmo tempo em que a necessidade de estabelecimento de elos que viabilizem diálogos necessários à geração de ordens culturais mais democráticas e plurais. [...] a mediação cultural apresenta-se, pois, como um território discursivo, de embates e possibilidades, ao mesmo tempo em que de afirmação de esfera pública como instância superior organizadora e legitimadora do campo simbólico (Perrotti, 2016, p. 13).

Entendemos, como Perrotti (2016), que a noção de mediação é uma categoria teórico-epistemológica que conecta os territórios da produção cultural com a recepção cultural.

\section{Considerações finais}

Se nos anos de 1990 Berta Ribeiro (1994) se preocupava com a possibilidade do desenvolvimento de pesquisas nas reservas técnicas dos museus etnográficos no Brasil, atualmente Athias e Gomes (2016) propõem outra problematização: compreender e conceituar museus indígenas numa perspectiva antropológica contemporânea. Lima Filho e Athias (2016, p. 80), por sua vez, suscitam outros questionamentos: "como fazer pesquisas nos museus envolvendo esses 'outros'? Como trazer suas preocupações para os museus?" Segundo eles, diferente dos museus comunitários que apresentariam narrativas na $1^{a}$ pessoa do singular, os museus etnográficos deveriam apresentar narrativas na $1^{\mathrm{a}}$ 
pessoa do plural, ou seja, "nós" - pesquisadores (antropólogos, museólogos e outros) com os detentores do patrimônio musealizado. Para eles, acervos estudados com indígenas ampliam a compreensão dos grupos indígenas sobre suas próprias culturas. Concordamos com esses autores que os acervos etnográficos são potentes elementos para despertar memórias e, em inúmeros casos, para contribuir em processos de revitalização cultural. Pensar os museus como zonas de contato, ou seja, como lugares de encontros e trocas entre profissionais dos museus, antropólogos, pesquisadores e os grupos representados pelos objetos musealizados, como sugere James Clifford (2016).

No Brasil, conforme Velthem (2012), iniciativas de experiências compartilhadas despontam entre povos indígenas de diferentes localidades, como no Mato Grosso do Sul, Amazonas, Amapá e Pará. Esses povos procuram se "(re)apropriar de acervos museais" (p. 62). A autora destaca também iniciativas de museus indígenas pensados como iniciativas indígenas.

Essas relações entre museus de antropologia, pesquisadores e povos indígenas nos levam a refletir sobre como são construídos esses processos no Brasil. Atualmente, são os desafios contemporâneos nestes circuitos de representação que despertam nossa atenção.

Como dissemos, para muitos ameríndios o conhecimento dos objetos acondicionados nos museus remete à memória de seus ancestrais e integra complexos processos de valorização de suas manifestações culturais. Em vários casos, isso implica garantir a transmissão de conhecimentos às futuras gerações. $O$ caso estudado das coleções etnográficas dos Katxuyana, em certa medida, revela tais aspectos.

Como sugerem Lima Filho e Athias (2016), Marilia Cury e Fabiola Silva (2008), e outros, vimos surgir no Brasil diferentes processos museológicos que inauguraram novas práticas na relação dos museus com os povos indígenas. $\mathrm{Na}$ descolonização, o museu é compreendido como cúmplice e não exclusivamente como autoridade e lugar de representação do "outro".

Por isso, vemos hoje se configurar um enorme desafio para os museus de antropologia e para os pesquisadores no que diz respeito aos processos museológicos voltados para uma mediação com os povos indígenas, procurando acolher suas demandas e expectativas. Nas palavras de Cury (2013, p. 473):

[...] orientar-se por suas perspectivas constitui um modelo museal de prática social, isto é, da formação das coleções às exposições a presença indígena é essencial. Paralelamente, diversos grupos indígenas passam a procurar os museus etnográficos para ver, rever, conhecer ou (re)aprender técnicas, a partir de coleções de artefatos ou registros fotográficos dos seus povos no passado, gerando um movimento de reconhecimento institucional e apoio à preservação cultural indígena.

Assim, se antes os indígenas eram tratados como não público ou público externo, essas experimentações ampliam a participação indígena nos processos museais. E é exatamente nesse último sentido apontado por Cury (2013), o da ação aberta que se constrói em processos de cooperação e conexões, aquele que tem despertado nossa atenção. 
Por fim, entendemos que um museu etnográfico não se esgota ou não deveria se esgotar na conservação, distribuição ou circulação dos signos que estão sob sua guarda. Acreditamos que os museus etnográficos têm uma potência enorme, ainda pouco explorada. Esta potência que transcende o próprio museu remete ao que Chagas e Gouveia (2014) assinalam sobre a formação política de indivíduos ou comunidades. Consideramos que essa potência pode ser desencadeada por processos museológicos compartilhados com diferentes sujeitos, como por exemplo, com os grupos indígenas. Dessa forma, apostamos na mediação cultural como base para uma prática contra-hegemônica sem desconsiderar as hierarquias e assimetrias entre os diferentes sujeitos e instituições, a saber: museus, grupos indígenas e pesquisadores.

\section{Referências}

ABREU, Regina. A patrimonialização das diferenças e os novos sujeitos de direito coletivo no Brasil. Relatório de pesquisa "Patrimonialização das diferenças: a categoria conhecimento tradicional e os novos sujeitos de direito coletivo no Brasil” ao CNPq. Rio de Janeiro, 2012.

Museus etnográficos e práticas de colecionamento: antropofagia dos sentidos. Revista do Patrimônio Histórico e Artístico Nacional, v. 31, p. 100-125, 2005b.

Quando o campo é o patrimônio: notas sobre a participação de antropólogos nas questões de patrimônio. Sociedade e Cultura, Goiânia, v. 8, n. 2, p. 37-52, jul./dez. 2005a.

. Tal antropologia, qual museu? In: ABREU, Regina; CHAGAS, Mário de Souza (Org.). Museus, coleções e patrimônios: narrativas polifônicas. Rio de Janeiro: Garamond/MinC/IPHAN/Demu, 2007. p. 138-178.

AMES, Michael McClean. Cultural empowerment and museum: opening up anthropology through collaboration. SuanPerace (Ed.). News Research in Museum Studies: objects of knowlodge. Athlone: London, 1990. v. 1. p. 158173.

ANDERSON, Benedict. Comunidades imaginadas: reflexões sobre a origem e a difusão do nacionalismo. São Paulo: Companhia das Letras, 2008.

ARANTES NETO, Antonio Augusto. Prefácio. Revista do Patrimônio Histórico e Artístico Nacional (Museus), v. 31, 2005.

ATHIAS, Renato. Museus, objetos etnográficos e pesquisa antropológica: um debate atual. Revista Anthropológicas, ano 19, v. 26, n. 1, p. 231-250, 2015.

; GOMES, Alexandre. Coleções etnográficas, museus indígenas e processos museológicos. Recife: EDUFPE, 2016.

BELTRÃO, Jane Felipe. Coleções etnográficas: chaves de muitas histórias. In: SEMINÁRIO DISCENTE DO MESTRADO EM GESTÃO DO PATRIMÔNIO DO INSTITUTO GOIANO DE PRÉ-HISTÓRIA E ANTROPOLOGIA, 2003, Goiás. Anais... Goiás: IGPA/UCG, 2003.

BHABHA, Homi. O local da cultura. Belo Horizonte: Ed. UFMG, 1998.

BOURDIEU, Pierre. A distinção: crítica social do julgamento. São Paulo: EDUSP; Porto Alegre: Zouk, 2007.

BYRNE, Sarah et al. (Ed.). Unpacking the collection: networks of material and social agency in the museum. New York: Dordrecht- Heidelberg-London, 2011.

CÂNDIDO, Manuelina Maria Duarte. Ondas do pensamento museológico brasileiro. Cadernos de sociomuseologia, Lisboa, Universidade Lusófona de Humanidades e Tecnologias, v. 20, n. 20, 2003.

CANNIZZO, Jeanne. Gathering souls and objects. Missionary collections. In: BARRINGER, Tim; FLYNN, Tom (Ed.). Colonialism and the object: empire, material culture and the museum. London: Routledge, 1998. p. 153-166. 
CARNEIRO DA CUNHA, Manuela. Cultura com aspas e outros ensaios. São Paulo: Cosac Naify, 2009.

CHAGAS, Mario; GOUVEIA, Inês. Museologia social: reflexões e práticas (à guisa de apresentação). Cadernos do CEOM, UNOCHAPECÓ, ano 27, n. 41, 2014. Disponível em: < https://bell.unochapeco.edu.br/revistas/index. $\mathrm{php} / \mathrm{rcc} / \mathrm{article} /$ download/2592/1523>. Acesso em: 9 ago. 2017.

CLIFFORD, James. A experiência etnográfica: antropologia e literatura no século XX. Rio de Janeiro: Ed. UFRJ, 2002.

Museums as contact zone. In: ROUTES: travel and translation in the late twentieth century. Cambridge: Harvard University Press, 1997. p. 188-219.

Museus como zonas de contato. Tradução Alexandre Barbosa de Souza, Valquiria Prates. Periodico Permanente, n. 6, 2016. Disponível em: <http://www.forumpermanente.org/revista/numero-6-1/conteudo/ museus-como-zonas-de-contato?searchterm=james+clifford $>$. Acesso em: 20 fev. 2017.

COELHO, Teixeira. Dicionário crítico de política cultura. São Paulo: Iluminuras, 2004.

CURY, Marilia Xavier (Org.). Direitos indígenas no museu: novos procedimentos para uma nova política - a gestão de acervos em discussão. São Paulo: USP; Brodowski: MAE, 2016 b.

Museus em conexões: reflexões sobre uma proposta de exposição. Revista IBICT, Brasília, v. 42, n. 3, p. 471-484, set./dez. 2013.

USP, 2016 a.

(Org.). Museus e indígenas: saberes e ética - novos paradigmas em debate. São Paulo: Brodowski: MAE/

CURY, Marilia Xavier; SILVA, Fabíola Andréa. O seminário "Museus, identidades e patrimônio cultural” MAE/ USP. Revista do Museu de Arqueologia e Etnologia, São Paulo, Suplemento 7, p. 4-8, 2008.

CURY, Marilia Xavier; VASCONCELLOS, Camilo de Mello; ORTIZ, Joana Montero. Questões indígenas e museus: debates e possibilidades. Brodowski: ACAM Portinari; MAE/USP; SEC/SP, 2012.

DESVALLÉES, André; MAIRESSE, François (Ed.). Conceitos-chave de museologia. Tradução de Bruno Brulon Soares e Marilia Cury. São Paulo: Comitê Brasileiro do Conselho Internacional de Museus; Pinacoteca do Estado de São Paulo; SECULT, 2013.

DIAS, Nélia. A antropologia ainda precisa de museus? Museologia E Interdisciplinaridade, Brasília, UnB, v. 2, n. 4, maio/jun. 2013. Disponível em: <http://periodicos.unb.br/index.php/museologia/article/view/9629/7108>. Acesso em: 20 fev. 2017.

DUARTE, Alice. Nova museologia: os pontapés de saída de uma abordagem ainda inovadora. Revista Eletrônica do Programa de Pós-Graduação em Museologia e Patrimônio da UNIRIO/ MAST, Rio de Janeiro, UNIRIO/MAST, v. 6, n. 1, 2013, p. 99-117. Disponível em: <http://revistamuseologiaepatrimonio.mast.br/index.php/ppgpmus/ article/viewFile/248/239>. Acesso em: 20 fev. 2017.

DUTRA, Mariana Ratts. Curadoria compartilhada na experiência de mediação cultural do Museu de Arte Contemporânea do Ceará. 2014. 105 f. Dissertação (Mestrado em Artes Visuais) - Centro de Artes e Comunicação, Universidade Federal de Pernambuco, Recife, 2014.

FRANÇOZO, Mariana; BROEKHOVEN, Laura van. Dossiê "Patrimônio indígena e coleções etnográficas”. Boletim do Museu Paraense Emilio Goeldi: Ciências Humanas, v. 12, n. 3, p. 709-711, set./dez. 2017.

GORDON, Cesar; SILVA, Fabíola Andréa. Objetos vivos: a curadoria da coleção etnográfica Xikrin-Kayapó no Museu de Arqueologia e Etnologia - MAE/USP. Estudos Históricos, Rio de Janeiro, n. 36, p. 93-110, 2005.

GRÜNEWALD, Rodrigo de Azeredo. Tradição. In: LIMA, Antonio Carlos de Souza (Coord.). Antropologia e direito: temas antropológicos para estudos jurídicos. Rio de Janeiro/ Brasília: Contra Capa/LACED/ABA, 2012. p. 186-197.

HALL, Stuart. Quando foi o pós-colonial? Pensando no limite. In: SOVIK, Liv. (Org.). Da diáspora. Identidades e mediações culturais. Belo Horizonte: Ed. UFMG, 2009. p. 95-120. 
HARKIN, Michael. Object lessons: the question of cultural property in the age of repatriation. Journal de la Societé des Americanistes, v. 91, n. 2, p. 9-29, 2005.

HARRISON, Rodney. Reassembling the collection: ethnografic museums and indigenous agency. New Mexico: SAR Press, 2013.

IBRAM - INSTITUTO BRASILEIRO DE MUSEUS. Guia dos museus brasileiros. Brasília, 2011.

Pontos de memória: metodologia e práticas em museologia social. IBRAM/ Organização dos Estados Ibero-americanos. Brasilia: Phábrica, 2016.

KAPLAN, Flora. Museum anthropology. In: LEVINDON, David; EMBER, Melvin. (Ed.). Encyclopaedia of cultural anthropology. New York: Henry Holt and Co, 1996. p. 813-817.

KREPS, Christina Faye. Liberating culture: cross-cultural perspective on museums, curation and heritage preservation. London: Routledge, 2003.

LAGROU, Els (Org.). No caminho da miçanga: um mundo que se faz de contas. Rio de Janeiro: Museu do Índio, 2016. Catálogo.

LIMA FILHO, Manuel; ATHIAS, Renato. Dos museus etnográficos às etnografias dos museus: o lugar da antropologia na contemporaneidade. In: RIAL, Carmen; SCHWADE, Elisete (Org.). Diálogos antropológicos contemporâneos. Rio de Janeiro: ABA, 2016. p. 71-83.

LONETREE, Amy. Decolonizing museums: representing native America in National and Tribal Museums. Chapel Hil: University of North Carolina, 2012.

MESTRE, Joan Santacana; CARDONA, Francesco Xavier Hernández. Museologia crítica. Gijón:Trea, 2006.

MOUTINHO, Mario Canova. Sobre o conceito de museologia social. Cadernos de Museologia, Porto, n. 1, 1993. Disponível em: <http://revistas.ulusofona.pt/index.php/cadernosociomuseologia/article/view/467> . Acesso em: 9 ago. 2017.

MUSEU DO ÍNDIO. Seminário "Gestão de acervos culturais em centros de formação, documentação, de cultura e Museus Indígenas no Brasil”. Documento final. Saquarema: Funai, 2013.

PERROTTI, Edmir. Mediação cultural: além dos procedimentos. In: SALCEDO, Diego Andres. Mediação cultural. São Carlos: Pedro \& João Editores, 2016. p. 6-14.

PRIOSTI, Odalice; MATTOS, Yára. Caminhos e percursos da museologia comunitária. Cadernos de museologia, n. 28, 2007, p. 71-92. Disponível em: <http://revistas.ulusofona.pt/index.php/cadernosociomuseologia/article/ view/513/416>. Acesso em: 10 nov. 2014.

RIBEIRO, Berta. Etnomuseologia: da coleção à exposição. Revista do Museu de Arqueologia e Etnologia, São Paulo, n. 4, p. 189-201, 1994.

RUSSI, Adriana. Tamiriki, pata yotonokwama: a reconstrução de uma casa, a valorização de uma cultura e o protagonismo dos ameríndios Kaxuyana às margens do rio Cachorro (Orximiná/PA). 2014. Tese (Doutorado) Centro de Ciências Humanas e Sociais, Universidade Federal do Estado do Rio de Janeiro, Rio de Janeiro, 2014.

KIEFFER DØSSING, Astrid; ENDREFFY, Marcela. A mediação cultural no âmbito da educação patrimonial: coleções etnográficas em possíveis diálogos entre universidades, museus e os ameríndios Katxuyana. Acesso Livre, n. 6, jul./dez. 2016. Disponível em: < https://revistaacessolivre.files.wordpress.com/2016/12/revistaacesso-livre-nc2ba-6-julho-dezembro-de-2016.pdf> . Acesso em: 20 fev. 2017.

SAHLINS, Marshall. O "pessimismo sentimental” e a experiência etnográfica: por que a cultura não é um "objeto" em vias de extinção (parte 2). Mana: Estudos de Antropologia Social, Rio de Janeiro, v. 3, n. 2, p. 103-150, 1997.

SAID, Edward. Orientalismo: o Oriente como invenção do Ocidente. São Paulo: Companhia de Bolso, 2007.

SCHWARCZ, Lilia Katri Moritz. A "Era dos museus de etnografia” no Brasil: o Museu Paulista, o Museu Nacional e o Museu Paraense em finais do XIX. In: FIGUEIREDO, Betânia Gonçalves;VIDAL, Diana Gonçalves (Org.). Museus: dos gabinetes de curiosidades à museologia moderna. 2. ed. Belo Horizonte: Fino Traço, 2013. p. 119-143. 
SHEPARD, Glenn. Ethomuseology at the Goeldi Museum of Brazil. In: INTERNATIONAL CONGRESS OF AMERICANISTS, 54., 2012,Vienna, Austria. Anais... Vienna, Austria: University of Vienna, 2012.

; et al. Objeto, sujeito, inimigo, vovô: um estudo em etnomuseologia comparada entre os MebêngôkreKayapó e Baniwa do Brasil. Boletim do Museu Paraense Emilio Goeldi: Ciências Humanas, Belém, v. 12, n. 3, p. 765787, set./dez. 2017.

SILVEIRA, Flavio Leonel; BEZERRA, Marcia. Educação patrimonial - perspectivas e dilemas. In: LIMA FILHO, Manuel; ECKERT, Cornelia; BELTRÃO, Jane (Org.). Antropologia e patrimônio cultural - diálogos e desafios contemporâneos. Blumenau, SC: Nova Letra, 2007. p. 81-97.

SIMPSON, Moira. Introducing ethnomuseology: issues in the management of culturally-sensitive artefacts in museum collections. In: KELLY, Linda; BARRETT, Jennifer (Ed.). Proceedings of UNCOVER: Graduate research in the Museum Sector Conference, v. 1, p. 109-117, 2003.

STRÁNSKY, Zbynek Zbyslav. Untitled essay in "Interdisciplinarity in Museums. Museological Working Papers, v. 2, n. 19, 1981.

TAPSELL, Paul. Arohamai: whose museum? In: MARSTINE, Janet (Ed.). The routledge companion to museum ethics: redefining ethics for the twenty-first-century museum. London: Routledge, 2011. p. 85-111.

THOMAS, Nicholas. The museum as method. Museum Anthropology, v. 33, n. 1, p. 6-10, 2010.

TOMÀS, Agustí Andreu. Los museos de etnologia en Europa: entre la redefinición y la transformación. Ilha: Revista de Antropologia, v. 14, n. 1, 2, 2012. http://dx.doi.org/10.5007/2175-8034.2012v14n1-2p83

VARINE, Hugues de. As raízes do futuro: o patrimônio a serviço do desenvolvimento local. Porto Alegre: Medianiz, 2013.

VELTHEM, Lucia Hussak van. Objets de memóire: indiens, colletions et musées au Brésil. Arquivos do Centro Cultural Calouste Gulbenkian, n. 45, p. 133-149, 2003.

. O objeto etnográfico é irredutível? Pistas sobre novos sentidos e análises. Boletim do Museu Paraense Emilio Goeldi: Ciências Humanas, v. 7, n. 1, p. 51-66, jan./abr. 2012.

ZAVALA, L. La educación y los museos en una cultura del espetáculo. In: ENCUENTRO NACIONAL ICOM/ CECA, 2003, Zacatecas (México). La educación dentro del museo, nuestra propia educación. Zacatecas, México: ICOM México, CECA, 2003. 


\title{
Ethnographic collections, indigenous people and the representation: the changes in the museum process with the collaborative experiences
}

\begin{abstract}
From the recent cultural policies directed to Amerindian people and to the cultural heritage, and from the contributions of critical museology, we see the conflicts in the relations between museums, universities and Amerindians. In the context of indigenous peoples, as Lucia Van Velthem and Regina Abreu indicate, knowing the pieces made by their ancestors is one of the means to understand their past and reflect on their present and future. According these authors, in recent years, Amerindians have become aware of museums and their collections. At present, certain collaborative museum processes incorporate indigenous participation. The impacts of these experiences on the environment of anthropology museums and universities reveal a complex network of relationships and point to the challenges of this type of cultural mediation. With this, new questions are presented to researchers and the contemporary debate on the relationship between different actors, circuits and representation policies intensifies.
\end{abstract}

Keywords: Collaborative museology, indigenous people, ethnographic collections, cultural mediation, cultural heritage.

\section{Colecciones etnográficas, pueblos indígenas y prácticas de representación: los cambios en los procesos museales con las experiencias colaborativas}

\section{Resumen}

A partir de las recientes políticas culturales dirigidas a los pueblos indígenas y al patrimonio cultural y a partir de las contribuciones de la museología crítica, notamos los choques en las relaciones entre museos, universidades y amerindios. En el contexto de los pueblos indígenas, como apuntan Lucia Van Velthem y Regina Abreu, conocer las piezas fabricadas por sus antepasados es uno de los medios para comprender su pasado y reflexionar sobre su presente y futuro. De acuerdo con las autoras, en los últimos años los amerindios se concienciaron de los museos y de sus colecciones. En la actualidad, ciertos procesos museísticos colaborativos incorporan la participación de indígenas. Los impactos de esas experiencias en el ambiente de los museos de antropología y de las universidades revelan una compleja red de relaciones y apuntan hacia los retos de ese tipo de mediación cultural. Con eso, nuevas cuestiones son presentadas a los investigadores y se intensifica el debate contemporáneo sobre la relación entre los diferentes actores, circuitos y políticas de representación.

Palabras clave: Museología colaborativa, pueblos indígenas, colecciones etnográficas, mediación cultural, patrimonio cultural. 